\title{
Contribution of zooplankton lipids to the flux of organic matter in the northern Adriatic Sea
}

\author{
Mirjana Najdek ${ }^{1}$, Staša Puškarić ${ }^{1}$, Alexander B. Bochdansky ${ }^{2}$ \\ ${ }^{1}$ 'Ruđer Bošković' Institute, Center for Marine Research Rovinj, 52210 Rovinj, Croatia \\ ${ }^{2}$ Department of Marine Biology, Institute of Zoology, University of Vienna, Althanstr. 14, A-1090 Vienna, Austria
}

\begin{abstract}
Analyses of particulate material collected by sediment traps moored at a location in the northern Adriatic Sea in 1991 revealed the presence of zooplankton fatty acids, even though zooplankton and other 'swimmers' killed by the trap's preservative were carefully removed. Laboratory experiments were conducted to (1) prove the existence of zooplankton lipids within fecal pellets, (2) exclude the possibility of incomplete separation of swimmers and other material as eventual contamination with polyunsaturated fatty acids in fecal pellets, (3) evaluate the importance of zooplankton lipids to mass flux and (4) reveal the mechanisms which lead to excretion of undigested organic matter, in this case polyunsaturated fatty acids. Our results show that the main source of fatty acids found in mass flux were zooplankton lipid droplets inside fecal pellets. The predominant fatty acids of zooplankton fecal pellets were saturated acid 16:0, monounsaturated acid 18:1 and polyunsaturated acid 22:6. Lipid composition of fecal pellets was compared with those of zooplankton and phytoplankton. Aliquots of collected fecal pellets were stained with Nile Red in order to visualize lipid droplets within fecal pellets.
\end{abstract}

KEY WORDS: Zooplankton · Fecal pellets · Fatty acids $\cdot$ Sediment traps $\cdot$ Lipid droplets

\section{INTRODUCTION}

Passively sinking large organic aggregates (mass flux) are one of the major mechanisms which control cycling of organic matter in the sea. One important factor regulating the mass flux in the sea is zooplankton, influencing sedimentation via production of large particles, e.g. fecal pellets (Fowler \& Knauer 1986, Noji 1991). These are discrete dense packages of diverse material, sometimes enclosed in a peritrophic membrane (Gauld 1957).

The mass flux is estimated by direct collection of sinking particles over a chosen time interval, e.g. days to months. For this purpose sediment traps are commonly used by oceanographers worldwide (Knauer et al. 1979, Honjo 1980). Chemical analyses of collected particles with the 'swimmers' separated are necessary because these animals actively enter the traps within the upper $500 \mathrm{~m}$ and are killed by the trap's preservative, causing errors in the assessment of mass flux (Honjo 1980, Knauer et al. 1984, Harbison \& Gilmer 1986, Lee et al. 1988, Hargrave et al. 1989, Michaels et al. 1990). To avoid such errors, zooplankton and all other swimmers should be carefully removed from samples.

Our analyses of 'swimmer-free' particles collected by sediment traps positioned in the northern Adriatic Sea during 1991 revealed very similar composition to that of zooplankton. The principal goal of this study was to identify the source of these fatty acids found in sediment trap material. Our assumption was that the major source of this material was zooplankton lipid droplets which remain 'trapped' in fecal pellets. Earlier studies concerned with qualitative changes in organic composition of the plant food as it passes through the guts of the animals have been particularly important for identifying organic inputs, especially lipids, to marine sediments (Tanoue et al. 1982, Prahl et al. 1984, Volkman et al. 1989). To test this hypothesis we conducted laboratory experiments and collected fecal pellets from fresh natural zooplankton community as described by Bochdansky \& Herndl (1992) and immediately analyzed for fatty acids by gas chromatography. In addition we compared the fatty acid composition in the 
fecal pellets from copepods fed on phytoplankton monocultures of green algae Dunaliella sp., eustigmatophyte Nannochloropsis sp. (marine Chlorella sp.) and prymnesiophyte Isochrysis sp. under controlled laboratory conditions, to elucidate the influence of the zooplankton diet on the fatty acid composition of the fecal pellets and to eliminate any doubts that trap samples separated from swimmers were eventually contaminated with zooplankton fragments, moults, eggs or other artifacts which might serve as a source of polyunsaturated fatty acids (PUFA).

Aliquots of collected fecal pellets were stained with Nile Red (NR) for epifluorescence microscopy. NR is a hydrophobic fluorophore that binds specifically to neutral lipids (Fowler \& Greenspan 1985, Cooksey et al. 1987). When viewed under epifluorescent illumination, lipid droplets stained by NR show a bright yellow/ orange fluorescence. The high specificity of NR in staining lipids makes it an ideal alternative to chemical extraction techniques (Carman et al. 1991) for determining neutral lipids

\section{MATERIAL AND METHODS}

Sediment trap samples: in situ experiment. Sediment trap samples were collected at a station in the northern Adriatic Sea $\left(45^{\circ} 2.8^{\prime} \mathrm{N}, 13^{\circ} 19.0^{\prime} \mathrm{E}\right)$. Trap openings were positioned at $23 \mathrm{~m}$ depth in a $37 \mathrm{~m}$ water column. Design of the trap system used is described by Puškarić et al. (1992). Traps were prefilled with brine solution containing $5 \%$ formalin to preserve the deposited material. Sediment traps were recovered monthly from 24 April to 5 August 1991.

Sedimented particles consisted of amorphous detrital material, fecal pellets and skeletal remains of various phytoplankton species. Traps contained numerous copepods and amphipods. All animals had intact antennae and tissue showing no signs of decomposition (observation before their removal), suggesting that they actively entered the trap and had been killed by the preservative. All swimmers were removed from the wet sample, prior to analysis, by small forceps with sharpened ends under a dissecting microscope at magnification 30 to $50 \times$. The samples were screened through $300 \mu \mathrm{m}$ mesh, from which larger swimmers were removed, and remaining particles were returned to the screened sample after the swimmer fraction $<300 \mu \mathrm{m}$ was also removed.

Collection of fecal matter: NR procedure and ieeding experiment. The zooplankton community used for the experiment was collected by hauling a net $(1 \mathrm{~m}$ mouth diameter, $250 \mu \mathrm{m}$ Nitex mesh) horizontally through the top $5 \mathrm{~m}$ for $2 \mathrm{~min}$ at the station located 1.5 nautical miles west of Rovinj. Croatia, in June
1992 and March to June 1993. Material in the collection cup was rinsed by 21 Whatman GF/F filtered seawater (FSW) and placed in a tank with $5 \mathrm{l}$ FSW. Zooplankton were starved for at least $2 \mathrm{~h}$ in order to empty the guts. Upon arrival in the laboratory, the zooplankton size fraction between $200 \mu \mathrm{m}$ and $1 \mathrm{~mm}$ was separated by screening collected zooplankton through $1 \mathrm{~mm}$ mesh and then rinsing onto $200 \mu \mathrm{m}$ mesh by passing the sample and $10 \mathrm{I} \mathrm{GF/F} \mathrm{FSW} \mathrm{over}$ the separated zooplankton. Microscopic examination revealed that most of the guts were empty. A $1 / 4$ aliquot of the total separated and rinsed zooplankton sample was filtered onto preweighed GF/F filter, rinsed 3 times with $200 \mathrm{ml}$ distilled water and dried at $50^{\circ} \mathrm{C}$ for $24 \mathrm{~h}$ for dry weight estimates. The remaining material was added to the 81 phytoplankton culture. The tank was rolled on a rolling table (Shanks \& Edmondson 1989), at slow speed (4 rpm) in the dark for $12 \mathrm{~h}$ at $22^{\circ} \mathrm{C}$. Zooplankton were then isolated from the tanks by screening $(200 \mu \mathrm{m})$, separated from the culture material with $10 \mathrm{lGF} / \mathrm{F}$ FSW and placed in the collection funnels in GF/F FSW. Aliquots of the fecal pellets were analyzed by gas chromatography or stained with NR, respectively, viewed under epifluorescence microscopy and subsequently filtered on preweighed GF/F filter for dry weight estimates. Zooplankton from collection funnels were filtered on precombusted GF/F filters and extracted as for gas chromatography analysis. The procedure was the same in all feeding experiments, including feeding on algal monocultures. Fecal pellets were collected using plexiglass funnels screened with a $120 \mu \mathrm{m}$ nylon mesh (Bochdansky \& Herndl 1992). The zooplankton community mainly consisted of small copepods Acartia clausi (more than 95\%). Collected fecal pellets were examined under a dissecting microscope at 30 to $50 \times$ magnification prior to filtration on precombusted $\left(380^{\circ} \mathrm{C}\right.$ for $\left.2 \mathrm{~h}\right) \mathrm{GF} / \mathrm{F}$ glass fibre filters. Microscopic examination revealed that the samples were free from contamination of alternative sources of PUFA, e.g. zooplankton fragments, moults, eggs or other artifacts. The types of fecal pellets found most commonly in our experiments are shown in Fig. 1. Subsequently, the filters with fecal pellets were extracted.

For NR staining of fecal pellets the collected zooplankton community was starved in GF/F FSW in collection funnels for $30 \mathrm{~min}$. Fecal pellets were suspended in $5 \mathrm{ml} \mathrm{GF/F} \mathrm{FSW} \mathrm{and} 100 \mu \mathrm{l} \mathrm{NR}$ stock solution $(2.5 \mathrm{mg}$ of $\mathrm{NR}$ added to $100 \mathrm{ml} \mathrm{p.a.} \mathrm{grade} \mathrm{ace-}$ tone) was added to fecal pellet suspension. Staining of neutral lipids was complete after $30 \mathrm{~min}$. Fecal pellets were examined at $400 \times$ using a Nikon Microphot SA microscope with an epifluorescence attachment. A standard blue excitation method was used (main wavelength $495 \mathrm{~nm}$ ), consisting of Nikon excitation 

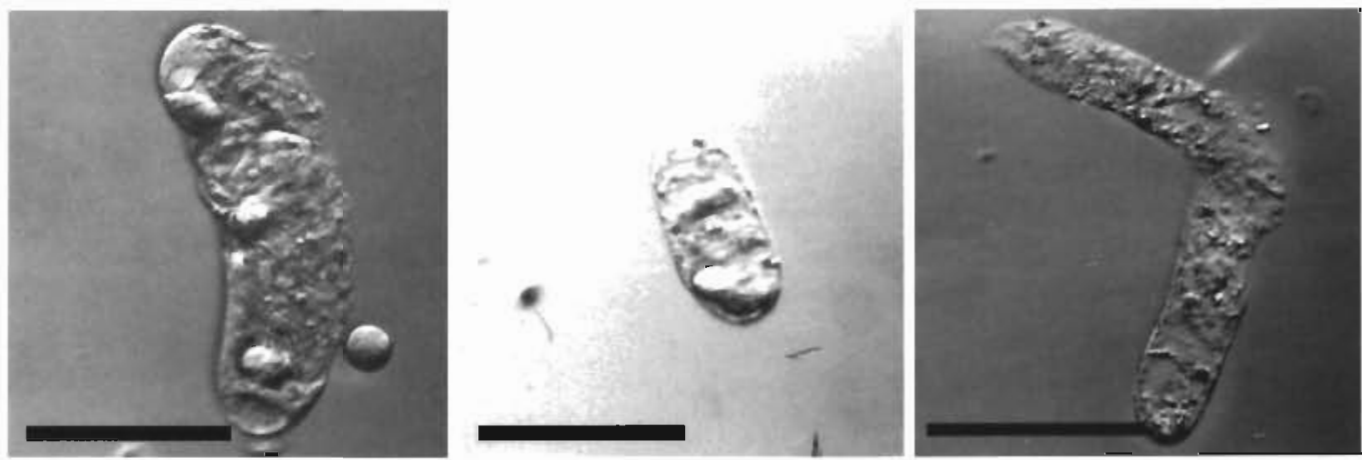

Fig. 1. Most common types of fecal pellets collected in this experiment. Scale bars $=50 \mu \mathrm{m}$

filter EX420-490, dichroic mirror DM510 and barrier filter BA520.

For obtaining natural algal cultures, seawater was taken at the sampling site at $5 \mathrm{~m}$ depth. Natural phytaplankton culture used in the feeding experiment was mainly composed of Chaetoceros sp. To remove larger grazers, the water sample was screened through a $200 \mathrm{\mu m}$ nylon mesh. Cultures (including phytoplankton monocultures of green algae Dunaliella sp., eustigmatophyte Nannochloropsis $\mathrm{sp}$. and prymnesiophyte Isochrysis sp.) were maintained in 10 l glass bottles (8 l in each tank) in SN medium (Waterbury et al. 1986) at $22^{\circ} \mathrm{C}$ and constant irradiation of $320 \mu \mathrm{E} \mathrm{m} \mathrm{m}^{-2} \mathrm{~s}^{-1}$ mixed by air bubbling. After the response of the algal community to increased concentrations of nutrients during the exponential phase of growth, at cell densities of

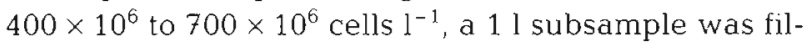
tered onto precombusted GF/F filters for gas chromatography analysis, $200 \mathrm{ml}$ for dry weight estimates (filtered onto preweighed $\mathrm{GF} / \mathrm{F}$ filter) and $5 \mathrm{ml}$ for phytoplankton cell counts.

Cell counts and dry weight estimates of the phytoplankton culture were done before and after removing the zooplankton from the culture. Cell counts were done at $400 \times$. For dry weight estimates, $200 \mathrm{ml}$ of culture was filtered onto preweighed GF/F filters, rinsed with distilled water and dried at $50^{\circ} \mathrm{C}$ for $24 \mathrm{~h}$. The filters were cooled to room temperature in a desiccator for $2 \mathrm{~h}$ prior to weighing.

Extraction and analysis. Lipid fractions were obtained from wet samples (up to $1 \mathrm{~g}$ dry wt) filtered onto precombusted $\left(380^{\circ} \mathrm{C}\right.$ for $\left.2 \mathrm{~h}\right) \mathrm{GF} / \mathrm{F}$ filters by Soxhlet extractions with dichloromethane (DCM)/methanol 2:1 $(\mathrm{v} / \mathrm{v})$ for $24 \mathrm{~h}$ (Leenheer 1981). The extracts were partitioned into aqueous and organic phases in separatory funnels by addition of water and DCM, and the waterphase was extracted repeatedly. The extracts were concentrated in a rotary evaporator at a temperature $<40^{\circ} \mathrm{C}$, and transferred into $50 \mathrm{ml}$ screw-capped centrifuge tubes and saponified with $15 \mathrm{ml} 1 \mathrm{~N} \mathrm{KOH}$ in methanol. The tubes were sealed and heated to $100^{\circ} \mathrm{C}$ for $30 \mathrm{~min}$. Fatty acids were methylated by adding $10 \mathrm{ml}$ of methanolic $\mathrm{BF}_{3}$ and the sealed tubes were heated for $5 \mathrm{~min}$ at $100^{\circ} \mathrm{C}$. Lipid components were then extracted with hexane, evaporated and transferred into a glass column packed with $2 \mathrm{~g}$ of $5 \%$ deactivated aluminum oxide over $2 \mathrm{~g}$ of $5 \%$ deactivated silica (70-140 mesh, Sigma). The column was successively eluted with $10 \mathrm{ml}$ hexane, $10 \mathrm{ml}$ 85:15 hexane:benzene and $8 \mathrm{ml}$ benzene. The fractionation procedure yielded eluants containing aliphatic, aromatic hydrocarbons and fatty acid methyl esters. After evaporation in a stream of nitrogen, each fraction was analyzed using a Hewlett Packard 5730A gas chromatograph and a glass capillary column, coated with methylsilicone $(12 \mathrm{~m} \times 0.2 \mathrm{~mm})$, programmed from $70^{\circ} \mathrm{C}$ to $270^{\circ} \mathrm{C}$ at a rate of $4^{\circ} \mathrm{C} \mathrm{min}-1$. Injector and detector temperatures were $250^{\circ} \mathrm{C}$ and $300^{\circ} \mathrm{C}$, respectively. Nitrogen was used as the carrier and make-up gas. Peaks were identified by means of reference standard mixtures of fatty acid methyl esters and by comparing relative retention times. The compounds were quantified by internal standard heptadecanoic acid $C_{17.0}$ for fatty acids. The internal standard was added before extraction.

The reproducibility was within $6 \%$ for fatty acids for triplicate samples. Recovery efficiencies ranged from 69 to $96 \%$ for fatty acids. Blank readings were made daily; all glassware was kept in hot sulfochromic acid and rinsed thoroughly with distilled water and DCM before use.

\section{RESULTS}

Mass fluxes of particles collected by sediment traps are given in Table 1, ranging from 0.55 to $0.93 \mathrm{~g}$ dry wt $\mathrm{m}^{-2} \mathrm{~d}^{-1}$, as well as total lipids, fatty acids, PUFA and the total fraction of unsaturated fatty acids. Fatty acid composition observed in sediment trap samples 

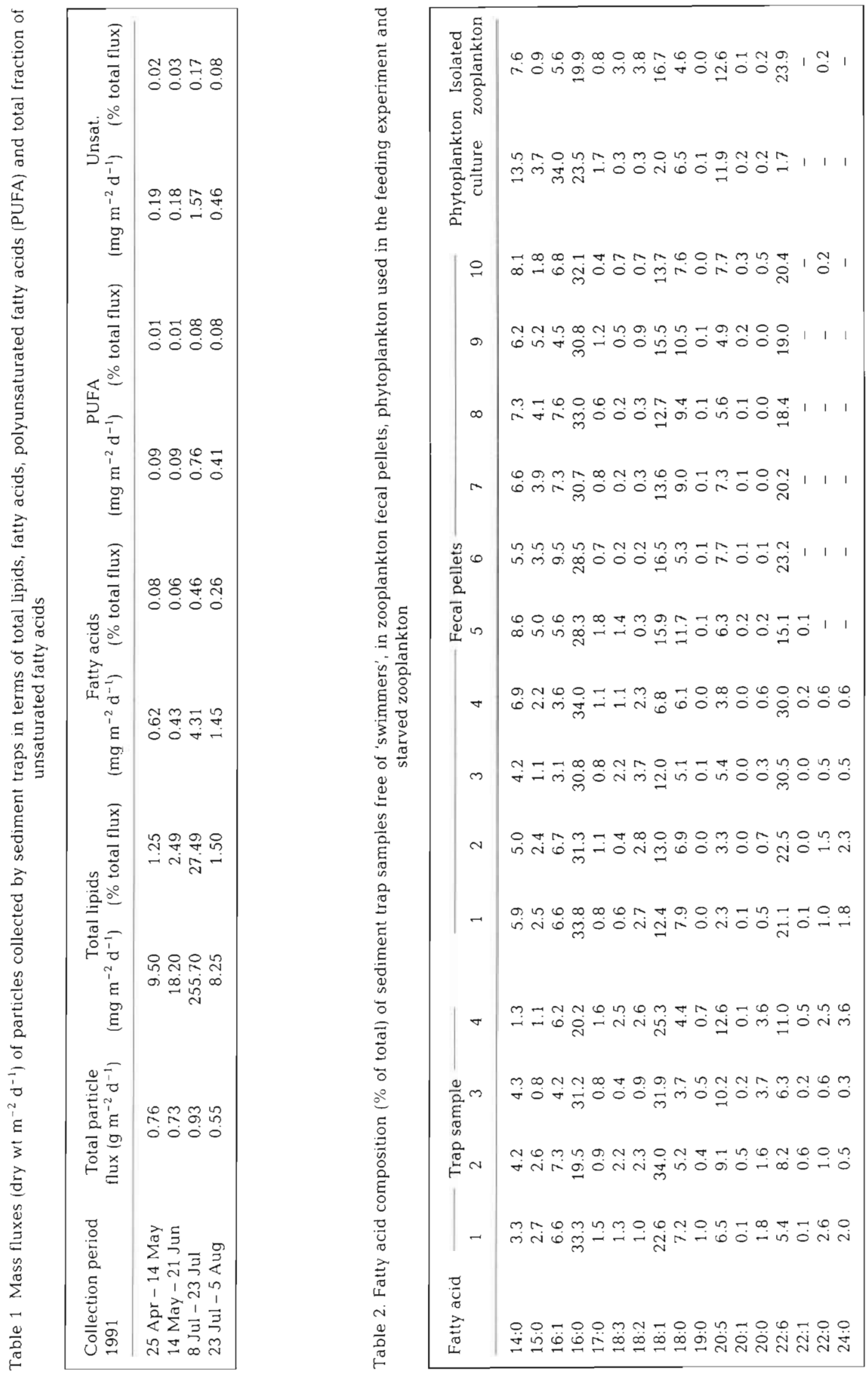
was similar to the composition found in fecal pellets (Table 2), i.e, both containing high proportions of PUFA with 20 and $22 \mathrm{C}$ atoms. This similarity is additionally confirmed by the cluster analysis dendrogram shown in Fig. 2. The dendrogram is based on the composition of fatty acids of fecal pellets (FP 1 to 13), zooplankton (ZOO 1 to 4 ; ZOO1 was fed with natural phytoplankton culture, ZOO2 with Dunaliella sp., ZOO3 with Nannochloropsis sp, and ZOO4 with Isochrysis sp.), natural phytoplankton culture (PHYTO), Dunaliella sp. (DUN), Nannochloropsis sp. (NAN), Isochrysis $\mathrm{sp}$. (IS) and sediment trap samples (TRAP 1 to 4 ), and the most similar samples are grouped and sorted by the complete linkage method (farthest neighbor). There are 3 distinct groups, of which one represents fecal pellets and zooplankton, one sediment trap samples and one phytoplankton cultures used in the experiments. Fig. 2 shows that fecal pellets are similar to each other and most similar to zooplankton and sediment trap samples. Most importantly, Fig. 2 shows that the phytoplankton cultures

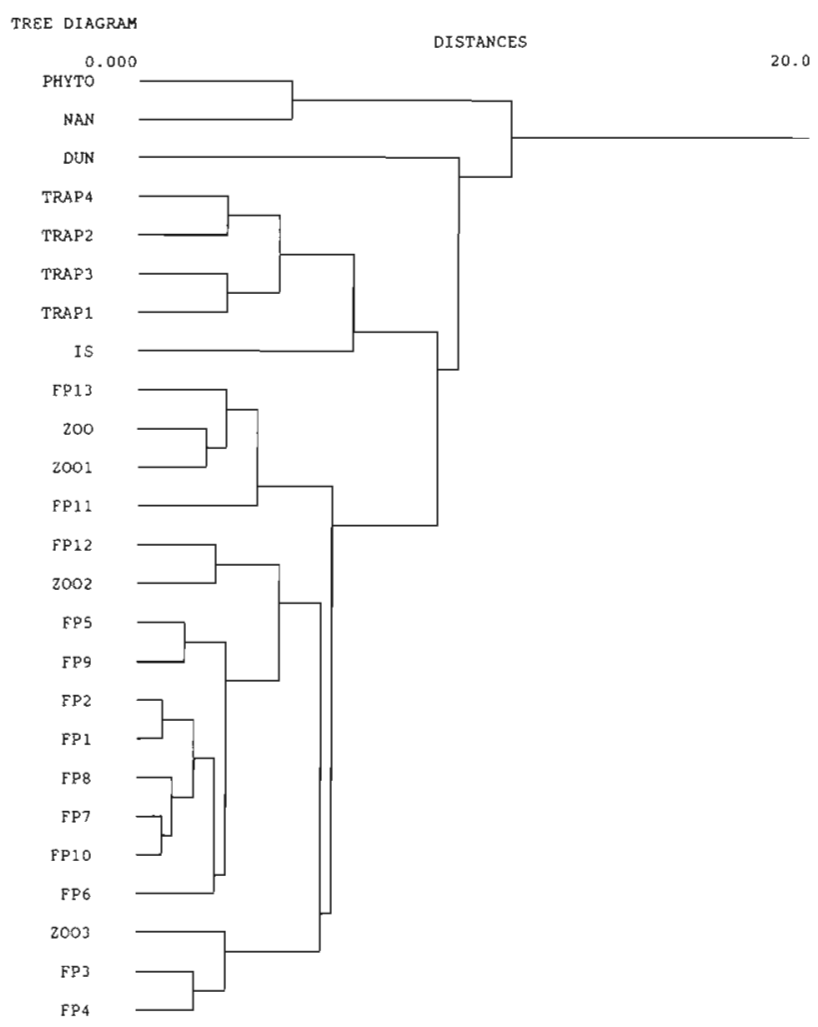

Fig. 2. Cluster analysis dendrogram (complete linkage method - farthest neighbor) of fatty acid composition of sediment trap samples (TRAP), zooplankton fecal pellets (FP). natural phytoplankton culture (PHYTO), Dunaliella $\mathrm{sp}$. (DUN), Nannochloropsis sp. (NAN), Isochrysis sp. (IS) and starved zooplankton (ZOO; ZOO1: then fed with PHYTO; ZOO2: fed with DUN; ZOO3: fed with NAN; ZOO4: fed with IS). Distance metric is Euclidean distance
Table 3. Summary statistics for 3 clusters, output data for dendrogram shown in Fig. 2. TRAP: sediment trap sample; FP: fecal pellet; PHYTO: phytoplankton culture ${ }_{i}$ ZOO: starved zooplankton; DUN: Dunaliella sp; NAN: Nannochloropsis sp.i IS: Isochrysis sp.

\begin{tabular}{|c|c|c|}
\hline Variable & $F$-ratio & Probability \\
\hline TRAP1 & 38.739 & 0.000 \\
\hline TRAP2 & 16.322 & 0.000 \\
\hline TRAP3 & 24.232 & 0.000 \\
\hline TRAP4 & 22.145 & 0.000 \\
\hline FP1 & 76.326 & 0.000 \\
\hline FP2 & 75.818 & 0.000 \\
\hline FP3 & 50.988 & 0.000 \\
\hline FP4 & 34.152 & 0.000 \\
\hline FP5 & 35.123 & 0.000 \\
\hline FP6 & 54.856 & 0.000 \\
\hline FP7 & 47.558 & 0.000 \\
\hline FP8 & 51.076 & 0.000 \\
\hline FP9 & 59.696 & 0.000 \\
\hline FP10 & 53.007 & 0.000 \\
\hline PHYTO & 2.559 & 0.107 \\
\hline ZOO1 & 30.036 & 0.000 \\
\hline DUN & 7.639 & 0.004 \\
\hline ZOO2 & 49.883 & 0.000 \\
\hline FP11 & 47.276 & 0.000 \\
\hline NAN & 7.404 & 0.005 \\
\hline ZOO3 & 54.054 & 0.000 \\
\hline FP12 & 32.861 & 0.000 \\
\hline IS & 10.551 & 0.001 \\
\hline $\mathrm{ZOO} 3$ & 30.526 & 0.000 \\
\hline FP13 & 20.291 & 0.000 \\
\hline
\end{tabular}

are very distant from all other samples. Statistical support for Fig. 2 is shown in Table 3. From F-ratios it can be seen that phytoplankton cultures form a distinct group of samples, different from fecal pellets, sediment trap samples and zooplankton.

Natural phytoplankton culture used in the feeding experiment was mainly composed of Chaetoceros sp. with cell density $402 \times 10^{6}$ cells $\mathrm{l}^{-1}$; the fatty acid composition used in the feeding experiment contained a very low proportion of the polyunsaturated acid 22:6 (only $1.72 \%$; Table 2), while the concentrations of $16: 1$, $16: 0,14: 0$ and $20: 5$ fatty acids accounted for $83 \%$ of the total fatty acid composition. The $\mathrm{C}_{18}$ and $\mathrm{C}_{22}$ PUFA were minor constituents.

The major fatty acids of Isochrysis sp. were 14:0, 16:0, 18:1 and 22:6. A similar fatty acid composition was also reported in other prymnesiophytes (Volkman et al. 1989). The fatty acid composition of Dunaliella sp. was typical for most green algae, with $C_{16}$ and $C_{18}$ PUFA being most abundant. The major fatty acids were identified as 16:0,16:4, 18:2 and 18:3. A distinct feature of Dunaliella sp. was that it contained very small amounts of 20:5 and 22:6 PUFA. Nannochloropsis sp. contained fatty acids 16:0,16:1, 18:3 and 20:5 as major components, while 22:6 was found in traces. 
Fatty acid composition of zooplankton, isolated after starvation in fecal pellet collection funnels, showed high proportions of $16: 0$ and $18: 1$, and $20: 5$ and $22: 6$ PUFA (Table 2)

It should be pointed out that fatty acids in fecal pellets collected under natural, as well as under laboratory, conditions were very similar, dominated by $16: 0$, 18:1 and 22:6 fatty acids which varied between 59.3 and $73.3 \%$. A very high proportion of PUFA varied within a similar range to that found in zooplankton $(21.4$ to $35.9 \%)$.

The distinguishing characteristic of fecal pellets from zooplankton fed on Dunaliella sp. and Nannochloropsis $\mathrm{sp}$. was that the PUFA characteristic of the algal diet were absent. In contrast, the PUFA composition in fecal pellets showed a much closer resemblance to the zooplankton composition (Table 4)

Fig. 3 shows various types of lipid droplets entrapped within the pellet's membrane stained with NR, and Fig. 1 indicates the most frequent forms of fecal pellets which contained lipid droplets. The analysis of collected fecal pellets by epifluorescence microscopy revealed that 81 to $100 \%$ of the pellets contained on average 9 to 10 droplets per pellet (diameters 0.5 to $20 \mu \mathrm{m})$.

\section{DISCUSSION}

The fatty acid composition observed in sediment trap samples was characterized by a relatively low proportion of saturated fatty acids with $14 \mathrm{C}$ atoms and a much higher proportion of the unsaturated fatty acids with $18 \mathrm{C}$ atoms. The presence of diatoms was indicated with a high proportion of $20: 5$ fatty acid. A low proportion of the $16: 1$ fatty acid and $16: 1 / 16: 0$ ratio argues against the abundance of diatoms. But, as shown by Tanoue (1985), these low proportions characterized small sized-diatoms and fecal pellets. However, it was demonstrated that diatoms, as well as fecal pellets, contain a very low proportion of the polyunsaturated acid 22:6 (Tanoue 1985, Volkman et al. 1989). The 22:6 fatty acid found in our sediment trap samples was assumed to originate directly from zooplankton.

Moreover, the fatty acid composition of fecal pellets collected during our feeding experiments and from starved zooplankton fed in their natural environment in the northern Adriatic Sea was very similar, having an unusually high proportion of PUFA (Fig. 2, Table 2). Almost the same composition was observed in zooplankton fatty acids (Fig. 2, Table 2), being within the range given for various zooplankton species in Morris

Table 4. Fatty acid composition (\% of total) in fecal pellets (FP) of zooplankton (ZOO) fed with Dunaliella sp. (D), Nannochloropsis $\mathrm{sp}$. (NAN) and Isochrysis sp. (IS), respectively. TR: traces

\begin{tabular}{|c|c|c|c|c|c|c|c|c|c|}
\hline Fatty acid & $\mathrm{D}$ & 2.00 & $\mathrm{FP}$ & NAN & 200 & FP & IS & 200 & $\mathrm{FP}$ \\
\hline \multicolumn{10}{|l|}{ Saturated } \\
\hline 14:0 & 0.9 & 1.9 & 4.1 & 6.5 & 7.7 & 14.8 & 17.9 & 5.1 & 8.8 \\
\hline 15:0 & 1.7 & 1.8 & 6.5 & 2.2 & 9.6 & 3.8 & 1.3 & 0.9 & 0.7 \\
\hline $16: 0$ & 29.8 & 19.3 & 22.6 & 28.7 & 32.4 & 30.6 & 22.2 & 26.5 & 15.4 \\
\hline $17: 0$ & 2.3 & 0.9 & 5.8 & 0.1 & 4.4 & 2.1 & 0.6 & 0.2 & 0.2 \\
\hline $18: 0$ & 3.8 & 6.6 & 6.3 & 6.5 & 5.4 & 5.9 & 3.4 & 5.6 & 7.5 \\
\hline $20: 0$ & 0.3 & 0.6 & 1.1 & 0.1 & 1.2 & 1.3 & 0.3 & 0.7 & 1.1 \\
\hline $22: 0$ & TR & 0.4 & 1.5 & 0.1 & 1.6 & 2.1 & 0.2 & 0.3 & 0.3 \\
\hline $24: 0$ & TR & 0.2 & 1.7 & 0.1 & 1.4 & 1.6 & 0.2 & 0.3 & 0.1 \\
\hline Sum $\%$ & 38.8 & 31.7 & 49.6 & 44.3 & 63.7 & 62.2 & 46.1 & 39.6 & 34.1 \\
\hline \multicolumn{10}{|c|}{ Monounsaturated } \\
\hline $16: 1$ & 1.7 & 5.6 & 5.2 & 22.6 & 5.3 & 4.9 & 4.7 & 4.1 & 8.4 \\
\hline $18: 1$ & 11.4 & 18.3 & 14.5 & 5.1 & 10.3 & 10.9 & 17.8 & 8.8 & 14.1 \\
\hline $20: 1$ & 0.7 & 0.6 & 1.2 & 0.2 & 1.6 & 2.9 & 0.3 & 0.4 & 0.9 \\
\hline Sum $\%$ & 13.8 & 24.5 & 20.9 & 27.9 & 17.2 & 18.7 & 22.8 & 13.3 & 23.4 \\
\hline \multicolumn{10}{|c|}{ Polyunsaturated } \\
\hline $16: 3$ & TR & TR & TR & TR & $\mathrm{TR}$ & IR & 1.3 & $\mathrm{TR}$ & TR \\
\hline $16: 4$ & 16.8 & $T R$ & $T R$ & TR & TR & TR & TR & $\mathrm{TR}$ & TR \\
\hline $18: 2$ & 2.9 & 4.2 & 4.6 & 2.2 & 0.7 & 1.1 & 3.9 & 5.2 & 6.3 \\
\hline $18: 3$ & 23.5 & 6.1 & 4.7 & 13.7 & 0.7 & 1.9 & 2.1 & 4.4 & 4.6 \\
\hline $18: 4$ & TR & $\mathrm{TR}$ & TR & TR & 0.2 & 0.6 & 12.2 & 3.6 & 4.8 \\
\hline $20: 5$ & 3.1 & 8.6 & 5.4 & 11.5 & 4.8 & 4.6 & 0.5 & 7.9 & 6.1 \\
\hline $22: 5$ & TR & $T R$ & TR & $T R$ & 0.3 & 0.6 & 1.6 & 0.8 & 0.2 \\
\hline $22: 6$ & 1.1 & 24.9 & 14.8 & 0.4 & 12.4 & 10.3 & 9.5 & 25.2 & 20.5 \\
\hline Sum \% & 47.4 & 43.8 & 29.5 & 27.8 & 19.1 & 19.1 & 31.1 & 47.1 & 42.5 \\
\hline
\end{tabular}



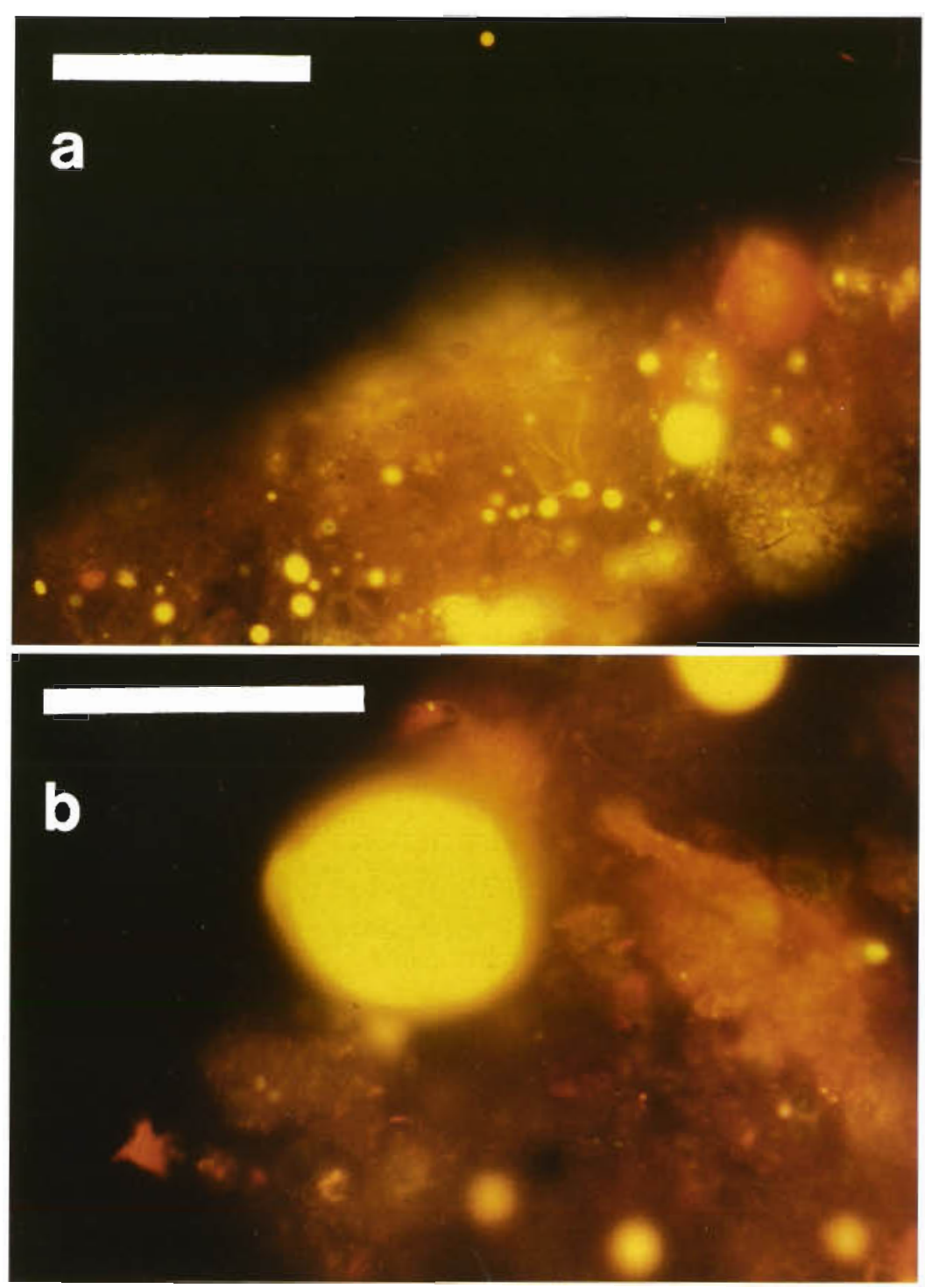

Fig. 3. (a) Numerous small lipid droplets within a fecal pellet, and (b) larger droplets entrapped in the pellet's membrane. Scale bars $=30 \mu \mathrm{m}$

showed that unsaturated fatty acids were found to be susceptible to digestion by zooplankton in laboratory experiments. In their experiments, fecal pellets showed very small proportions of 20:5 and 22:6 PUFA. Polyunsaturated fatty acids are a class of compounds that undergo considerable modification. The explanation proposed by Prahl et al. (1984), that animals selectively absorbed PUFA during digestion or that hydrogenation of fatty acids occurred within the gut itself, obviously contributes to the observed changes only for the PUFA taken from the diet. In our feeding experiment the percentage of characteristic dietetic PUFA $(16: 4,18: 3,18: 4$ which are abundant constituents in Dunaliella sp. and Nannochloropsis sp. respectively) was markedly reduced during the passage of the food material through the gut. In the case when an alternative source of 22:6 PUFA was present in the food, as with Isochrysis sp. (9.2\% of total), it was difficult to distinguish whether 22:6 PUFA found in fecal pellets originated from the diet or from the zooplankton itself

Based on the high abundance of lipid droplets in fecal pellets which we determined by means of the NR method, it can be speculated that the actual fatty acid composition of fecal pellets was masked by fatty acid composition of lipid droplets entrapped within the pellets' peritrophic membrane, pointing to the possibility that lipid droplets originated directly from the zooplankton and that contamina-

(1971). However, the analysis of natural phytoplankton culture and monocultures Dunaliella sp. and Nannochloropsis sp. on which the zooplankton were fed exhibited the lack of 22:6 PUFA. Alternative sources of 22:6 PUFA, such as dinoflagellates or some prymnesiophytes (Volkman et al. 1989), were not present in natural phytoplankton cultures dominated by Chaetoceros sp. This can serve as evidence that phytoplankton prey of zooplankton are not the source of the PUFA found in fecal pellets, even if it is present as a contaminant in fecal pellets.

This unusually high proportion of the 22:6 PUFA is inconsistent with the findings of Tanoue et al. (1982), Prahl et al. (1984) and Tanoue \& Hara (1986), who tion with zooplankton fragments, moults and eggs as the source of 22:6 PUFA can be excluded. The analysis of collected fecal pellets exhibited a high degree of volume variation of lipid droplets, e.g. 81 to $100 \%$ of the pellets contained 9 to 10 droplets per pellet, most probably directly related to the quantity and proportion of fatty acids in zooplankton.

Our experiments using natural conditions, as well as defined food sources, have shown that the composition of fatty acids in fecal pellets is very similar to zooplankton, i.e. the fatty acids remain unaltered in composition even after digestion. For this reason we assumed that the main source of fatty acids found in fecal pellets were zooplankton undigested lipids. The 
NR method indicated that lipid droplets found within fecal pellets (see Figs. 1 \& 2) most probably represent the undigested part of the total lipid content of zooplankton. The mechanism of zooplankton excretion of lipid droplets was previously discussed by Nott et al. (1985), explaining this phenomenon with the activity and disintegration of vacuolar B-cells (Arnaud et al. 1978). High abundance of lipid droplets in fecal pellets (and sediment trap samples) found in the northern Adriatic Sea might be related to high productivity of the investigated area, and thus higher grazing and activity of vacuolar B-cells, influencing high production and excretion of lipids in zooplankton guts.

In 1991 fecal pellets contributed up to $30 \%$ to the total mass flux in the northern Adriatic Sea (S. Puškarić \& S. W. Fowler unpubl. data). The notion that undigested PUFA can remain entrapped within the fecal pellet membrane in the form of droplets and appear as a component of mass flux (Table 1) indicates that the seafloor can be seeded by easily available organic matter. Additionally, entrapping of fecal pellets by marine snow and their subsequent remineralization by heterotrophs can also be an additional source of DOM for upper layers of the water column.

Moreover, including lipid droplets in the mechanism proposed in this paper has ecological significance not only in shallow waters such as the northern Adriatic Sea but might be operative even in greater depths as shown by Saliot et al. (1982) and Wakeham (1982), who found material characterized by biological printings of phytoplankton and zooplankton activities in the equatorial North Atlantic at $5082 \mathrm{~m}$ depth and in the Arabian Sea below $1000 \mathrm{~m}$ as a component of particulate material.

Acknowledgements. Financial support was given by the Ministry of Science and Technology of the Republic of Croatia (project no. 1-08-229) and Austrian Science Foundation (FWF project no. 7748). The help of the crew of RV 'Vila Velebita' is greatly appreciated. The authors also owe their gratitude to Gerhard J. Herndl for constructive comments and discussion.

\section{LITERATURE CITED}

Arnaud, J., Brunet, M., Mazza, J. (1978). Studies on the midgut of Centropages typicus (copepod, calanoid). Cell Tissue Res. 187: 333-353

Bochdansky, A. B., Herndl, G. J. (1992). Ecology of amorphous aggregations (manine snow) in the Northern Adriatic Sea. V. Role of zooplankton fecal matter. Mar. Ecol. Prog. Ser. 89: 297-303

Carman, K. R., Thistle, D., Ertman, S. C., Foy, M. (1991). Nile red as a probe for lipid-storage products in benthic copepods. Mar. Ecol. Prog. Ser 74: 307-311

Cooksey, K. E., Guckert, J. B., Williams, S. A., Callis, P. R. (1987). Fluorometric determination of the neutral lipid content of microalgal. cells using nile red. J. Microbiol. Methods 6: $333-345$
Fowler, S. D., Greenspan, P. (1985). Application of nile red, a fluorescent hydrophobic probe, for the detection of neutral lipid deposits in tissue sections: comparison with oil red $\mathrm{O}$. J. Histochem. Cytochem. 33: 833-836

Fowler, S. W., Knauer, G. A. (1986). Role of large particles in the transport of elements and organic compounds through the oceanic water column. Prog. Oceanogr. 16: 147-194

Gauld, D. T. (1957). A peritrophic membrane in calanoid copepods. Nature 179: 325-326

Harbison, G. R., Gilmer, R. W. (1986). Effects of animal behavior on sediment trap collections: implications for the calculation of aragonite fluxes. Deep Sea Res. 33: 655-674

Hargrave, B. T., von Bodungen, B., Conover, R. J., Fraser, A. J., Phillips, G., Vass, W. P. (1989). Seasonal changes in sedimentation of particulate matter and lipid content of zooplankton collected by sediment trap in the Arctic ocean off Axel Heiberg Island. Polar Biol. 9: 467-475

Honjo, S. (1980). Material fluxes and modes of sedimentation in the mesopelagic and bythypelagic zones. J. mar. Res. 38: 53-97

Knauer, G. A., Karl, D. M., Martin, J. H., Hunter, C. N. (1984). In situ effects of selected preservatives on total carbon, nitrogen and metals collected in sediment traps. J. mar. Res. 42: 445-462

Knauer, G. A., Martin, J. H., Bruland, K. W. (1979). Fluxes of particulate carbon, nitrogen, and phosphorus in the upper water column of the northeast Pacific. Deep Sea Res. 26: $97-108$

Lee, C., Wakeham, S. G., Hedges, J. I. (1988). The measurement of oceanic particle flux - are 'swimmers' a problem? Oceanography 1:34-36

Leenheer, M. J. (1981). Use of lipids as indicator of diagenetic and source related changes in Holocene sediments. Ph.D. thesis, Univ. of Michigan

Michaels, A. F., Silver, M. W., Gowing, M. M., Knauer, G. A. (1990). Cryoptic zooplankton 'swimmers' in upper ocean sediment traps. Deep Sea Res. 37: 1285-1296

Morris, R. J. (1971). Variations in the fatty acids composition of oceanic euphausiids. Deep Sea Res. 18: 525-529

Noji, T T. (1991). The influence of macrozooplankton on vertical particulate flux. Sarsia 76: 1-9

Nott, J. A., Corner, E. D. S., Mavin, L. J., O'Hara, S. C. M. (1985). Cyclical contributions of the digestive epithelium to faecal pellet formation by the copepod Calanus helgolandicus. Mar. Biol. 89: 271-279

Prahl, F. G., Eglinton, G., Corner, E. D. S., O'Hara, S. C. M., Forsberg, T. E. V. (1984), Changes in plant lipids during passage through the gut of Calanus. J. mar. biol. Ass. U.K. 64: $317-334$

Puškarić, S., Fowler, S. W., Miquel, J.-C. (1992). Temporal changes of particulate flux in the northern Adriatic Sea. Estuar coast. Shelf Sci. 35: 267-287

Saliot, A., Goutx, M., Fevrier, A., Tusseau, D., Andrie, C (1982). Organic sedimentation in the water column in the Arabian Sea: relationship between the lipid composition of small and large size, surface and deep particles. Mar. Chem. 11: 257-278

Shanks, A. L., Edmondson, E. W. (1989). Laboratory-made artificial marine snow: a biological model of the real thing Mar. Biol. 101: 463-470

Tanoue. E. (1985). Organic chemical composition of fecal pellet of the krill Euphausia superba Dana. I. Lipid composition. Trans Tokyo Univ. Fish. 6: 125-134

Tanoue, E., Handa, N., Sakugawa, H. (1982). Difference of the chemical composition of organic matter between fecal pellets of Euphausia superba and its feed Dunaliela tertiolecta. Trans Tokyo Univ. Fish. 5: 189-196 
Tanoue, E., Hara, S. (1986). Ecological implications of fecal pellets produced by the Antarctic krill Euphausia superba in the Antarctic Ocean. Mar. Biol. 91: 359-369

Volkman, J. K., Jeffrey, S. W., Nichols, P. D., Rogers G. I., Garland, C. D. (1989). Fatty acid and lipid composition of 10 species of microalgae used in mariculture. J. exp. mar. Biol. Ecol. 128: 219-240

Wakeham, S. G. (1982). Organic matter from a sediment trap

This article was submitted to the editor experiment in the equatorial North Atlantic: wax esters, steryl esters, triacylglycerols, and alkyldiacylglycerols. Geochim. Cosmochim. Acta 46: 2239-2257

Waterbury, J. B., Watson, S. W., Valois, F. W., Franks, D. G. (1986). Biological and ecological characterization of marine unicellular cyanobacterium Synechococcus. In: Platt, T., Li, W. K. W. (eds.) Photosynthetic picoplankton. Can. Bull. Fish. Aquat. Sci. 214: 71-120

Manuscript first received: September 27, 1993 Revised version accepted: April 18, 1994 